\title{
Formação de intérpretes na PUC-Rio: meio século de história ${ }^{1}$
}

\author{
Raffaella de Filippis Quental*
}

No ano do cinquentenário da criação da habilitação tradutor-intérprete no curso de Letras da PUC-Rio, pareceu-me oportuno refazer a trajetória percorrida pelo curso de formação de intérpretes, que começou como um bacharelado e é hoje uma pós-graduação lato sensu. Além de ser uma clara homenagem ao curso que formou tantas gerações de intérpretes que hoje são profissionais bem-sucedidos no Brasil e no exterior, este artigo pretende preencher uma lacuna na história da interpretação no Brasil ou mesmo corrigir algumas informações imprecisas já veiculadas.

O levantamento de dados objetivos e abrangentes sobre currículo, carga horária e conteúdo programático visa também a contribuir para a pesquisa em interpretação de conferências e, em particular, para a literatura sobre formação de intérpretes, cuja importância para a profissionalização é enfatizada por Sawyer (2004, p. 29) em seu livro Fundamental Aspects of Interpreter Education. ${ }^{2}$

\footnotetext{
${ }^{1}$ Agradeço a todas as pessoas que colaboraram para a realização deste artigo, dos funcionários do Departamento de Letras e do Núcleo de Memória da PUC-Rio aos professores, ex-alunos e colegas de várias gerações, que compartilharam generosamente seus arquivos e suas lembranças, e em especial a André Bekenn, pela parceria e confiança nesse percurso.

* Raffaella de Filippis Quental é tradutora e intérprete, mestre em Linguística Aplicada pela Unicamp, professora e coordenadora do Curso de Formação de Intérpretes de Conferência da PUC-Rio.

${ }^{2}$ At the same time, a considerable effort is required in documentation for general research purposes. A comprehensive, centralized database of curriculum documents, including in particular program and course descriptions and other writings that normally remain unpublished, would create a sound material basis for international research on translator and interpreter education and contribute greatly to professionalization.
} 
Vale lembrar também que a história da formação de intérpretes no Brasil é indissociável da história da profissão no país, o que ganha ainda maior relevância no caso do curso da PUC-Rio, que produziu uma parcela considerável dos intérpretes que ajudaram a configurar o mercado do Rio de Janeiro tal como é hoje.

Para reconstruir todos os passos desta memória recorri a documentos oficiais, como exemplares digitalizados do Catálogo Geral de anos diversos, que compõem o acervo do Núcleo de Memória da PUC-Rio, e os projetos de reformulação do curso arquivados no Departamento de Letras. Igualmente relevante foi a historiografia sobre tradução e interpretação no Brasil, além da ajuda preciosa dos antigos professores e alunos, que compartilharam comigo suas lembranças e documentos em depoimentos pessoais e também contribuíram com algumas das imagens que ilustram o texto.

Não é supérfluo mencionar meu envolvimento de mais de 30 anos, pessoal e profissional, com a instituição mencionada, primeiro como aluna da graduação e, a partir de 1996, como membro do corpo docente do Curso de Formação de Intérpretes da PUC-Rio. A posição de pesquisadora insider, à semelhança da abordagem de Pagura (Koskinen, apud Pagura 2010, p. 26/27) em seu estudo pioneiro sobre a história da interpretação de conferências no Brasil, me permite uma visão privilegiada de algumas das escolhas feitas nessa trajetória, bem como um entendimento mais perspicaz do que Sawyer (2004, p. 42) denomina "currículo oculto", ou seja, aqueles "valores e crenças que moldam os futuros membros da comunidade profissional" e que são transmitidos implícita ou explicitamente no curso, sem estarem necessariamente refletidos no currículo formal.

\section{Introdução}

Em 1968, em linha com a política desenvolvimentista iniciada alguns anos antes, foi promovida uma profunda reforma universitária no Brasil, que seria sedimentada com a promulgação da segunda Lei de Diretrizes e Bases da Educação Nacional (LDB) em novembro daquele ano. A LDB 5.540, também chamada de Lei da Reforma Universitária, que chegava numa época de forte expansão do comércio mundial, focava especificamente no 
ensino superior e forneceu o respaldo para a criação de novas habilitações no Bacharelado em Letras (à época chamadas de especializações). Explica Martins (2007, p. 175), em trabalho seminal sobre a institucionalização da tradução na PUC-Rio:

\begin{abstract}
A criação da então especialização em revisor-tradutor-intérprete deveu-se à identificação de novas perspectivas profissionais, que poderiam ser atendidas na medida em que se possibilitasse, aos bacharelandos, agregar a competência em tradução e em interpretação simultânea aos conhecimentos linguísticos e à formação humanística tradicionalmente associados à área de Letras.
\end{abstract}

Ao longo dos 50 anos que se passaram desde então, o curso sofreu transformações em vários níveis, passando de bacharelado a pósgraduação, com gradual expansão e consolidação do currículo, e conquistando um lugar incontestável na formação de intérpretes no Brasil. Essa história pode ser didaticamente dividida em 3 fases, que são apresentadas de maneira resumida na tabela abaixo e serão explicitadas a seguir, sempre que possível correlacionadas com o momento histórico da profissão e da formação de intérpretes no Brasil e no mundo.

\begin{tabular}{|c|c|c|c|c|}
\hline Fase & Ano & Status do curso & Duração & $\begin{array}{l}\text { Carga } \\
\text { horária }\end{array}$ \\
\hline \multirow{4}{*}{ Primórdios } & 1968 & Bacharelado: revisor-trad.-intérprete & 4 anos & -- \\
\hline & 1974 & Bacharelado: tradutor-intérprete & 4 anos & - \\
\hline & 1976 & $\begin{array}{l}\text { Bacharelado: tradutor-intérprete ou } \\
\text { tradutor }\end{array}$ & 4 anos & -- \\
\hline & 1978 & Bacharelado: intérprete & 4 anos & -- \\
\hline \multirow{4}{*}{$\begin{array}{l}\text { Expansão e } \\
\text { consolidação }\end{array}$} & 1985 & Bacharelado: reforma curricular & 4 anos & - \\
\hline & 1988 & Abertura para alunos de Extensão & 2 anos & 720 horas \\
\hline & $1998 ?$ & Aumento da carga horária & 2 anos & 840 horas \\
\hline & 2004 & Curso Sequencial & 2 anos & 870 horas \\
\hline \multirow{3}{*}{ Maturidade } & 2008 & Pós-graduação lato sensu & 2 anos & 930 horas \\
\hline & 2016 & $1^{\text {a }}$ reformulação curricular & $\begin{array}{c}1 \text { ano } \\
(+ \text { monografia })\end{array}$ & 400 horas \\
\hline & 2017 & $2^{a}$ reformulação curricular & $\begin{array}{c}1 \text { ano } \\
(+ \text { monografia })\end{array}$ & 510 horas \\
\hline
\end{tabular}




\section{Primórdios: a 1aa geração de intérpretes formados na PUC-Rio}

No mesmo ano de 1968 em que foi criada a LDB supracitada, Maria Candida Bordenave, após uma profícua experiência como intérprete no Peru e nos EUA -- onde fizera o curso de intérpretes da Universidade de Georgetown, em Washington, e trabalhara no Departamento de Estado por cerca de dois anos -- procurou a diretora do então Departamento de Letras e Artes em busca de uma oportunidade acadêmica. Sua chegada coincidiu com o momento em que o Departamento inaugurava as habilitações de revisor-tradutor-intérprete, assessor-secretário-executivo, crítico literário e pesquisador, e Bordenave logo foi colocada à frente da primeira em vista de sua experiência pregressa. As duas últimas habilitações desapareceram já no começo dos anos 1970; a de secretariado executivo continuou sendo oferecida até 2004, enquanto a primeira fincou raízes e evoluiu até se tornar parte da tradição do Departamento de Letras da PUC-Rio.

Como explica Martins (2007, p. 176), o currículo de Letras era composto por dois eixos, um com disciplinas comuns às licenciaturas e bacharelados e outro composto por disciplinas específicas da habilitação escolhida:

\footnotetext{
No caso do revisor-tradutor-intérprete, a grade previa as seguintes disciplinas específicas: tradução literária e tradução técnica, cada uma com 60 horas; interpretação simultânea, de 90 horas; versão escrita e língua portuguesa para tradução e interpretação, também de 60 horas cada; e os estágios supervisionados de tradução e interpretação, cada um com 105 horas.
}

Ainda segundo Martins, a primeira alteração da habilitação de revisor-tradutor-intérprete criada em 1968 foi a supressão do revisor em 1974. Dois anos depois, no catálogo de 1976, a habilitação já aparece desmembrada em tradutor-intérprete, de um lado, e tradutor, do outro, com disciplinas específicas das duas áreas, até que em 1978 a habilitação de tradutor-intérprete passou a se denominar somente Intérprete, embora continuasse incluindo disciplinas de tradução escrita, como veremos a seguir (Martins, 2007, p. 178-179). 
O Catálogo Geral de 1978 mostra que o Curso de Letras seguia o modelo em $\mathrm{Y}$ descrito acima por Martins, com um tronco de disciplinas obrigatórias comum aos bacharelados e à licenciatura e um segundo ciclo de disciplinas "de especialização". Estas previam 188 créditos para a habilitação de Intérprete (3.345 horas-aula), com sugestão de "prazo médio de 8 (oito) períodos letivos, ou seja, quatro anos letivos" (Catálogo Geral PUC-Rio, 1978, p. 100). Desses 188 créditos, 86 eram considerados específicos de interpretação, porém ainda incluíam disciplinas como "língua inglesa e literatura correspondente", "tradução" e "língua estrangeira paralela".

Sobre a prática de incluir disciplinas obrigatórias de tradução na formação do intérprete, certamente comum na época e ainda corrente em muitas escolas, afirma Seleskovitch (1999, p. 63):

\begin{abstract}
A razão pela qual a tradução e a interpretação devem ser ensinadas separadamente é que cada uma exige habilidades diferentes. A tradução não é um exercício preparatório para a interpretacão, assim como a interpretação não é um exercício preparatório para a tradução escrita. ${ }^{3}$ (tradução minha)
\end{abstract}

Embora a coordenação do curso de intérpretes estivesse plenamente de acordo, a prática ainda persistiu por vários anos, sendo compensada pelo incremento gradual das disciplinas verdadeiramente específicas, que será descrito mais adiante.

Digna de nota no currículo da época é a presença de um segundo idioma estrangeiro, como informa o Catálogo: "13 [créditos] poderão ser preenchidos com disciplinas de língua francesa (língua paralela obrigatória para a especialização Tradutor-Intérprete)" (Catálogo Geral PUC-Rio, 1974, p. 114). Veremos mais adiante que, embora deixasse de ser obrigatório, o domínio de uma segunda língua estrangeira sempre foi incentivado na formação de intérpretes da PUC-Rio.

\footnotetext{
${ }^{3}$ The reason why translating and interpreting should be taught separately is that each requires different skills. Translating is not a preparatory exercise for interpreting and similarly interpreting is not a preparatory exercise for written translation.
} 
A Figura 1 mostra a lista das disciplinas constantes do histórico de uma ex-aluna formada em 1977 que optou pelas duas habilitações ("especializações") -- Tradutor e Tradutor-Intérprete - tal como indicado no Apostilamento no verso do diploma (Figura 2). Chama atenção, nessa fase inicial de estruturação da área, o número reduzido de disciplinas específicas, a falta de precisão (misturando "tradução" com "interpretação consecutiva") no nome da disciplina Inglês (Tradução Consecutiva) e a junção de tradução e interpretação na mesma disciplina de Língua Portuguesa.

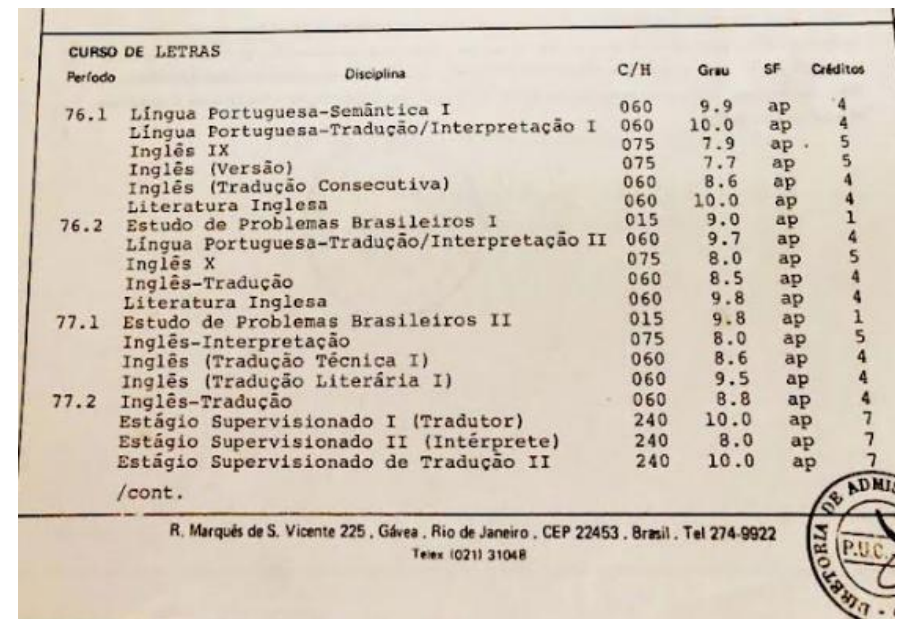

Figura 1: Histórico do Curso de Letras - 1977

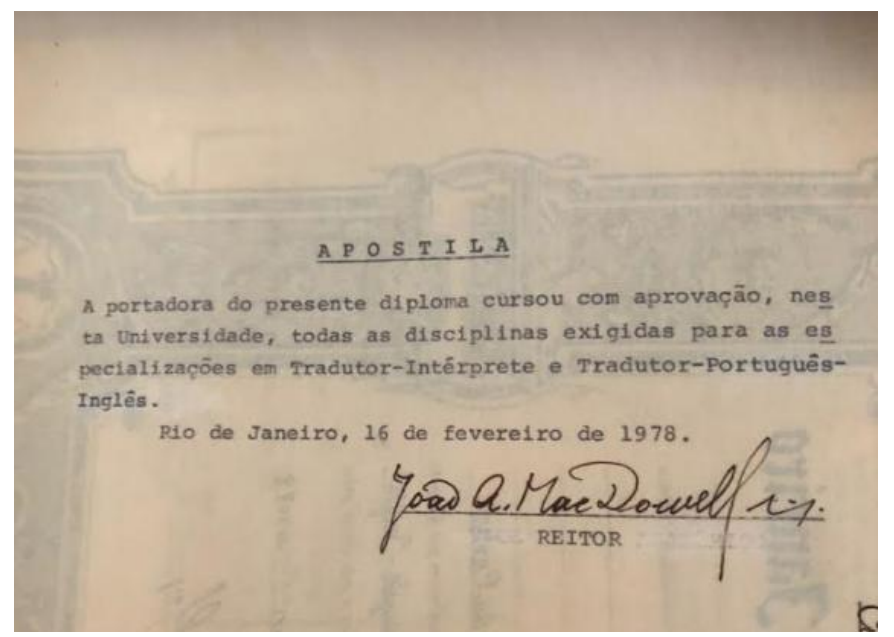

Figura 2: “APOSTILA - A portadora do presente diploma cursou com aprovação, nesta Universidade, todas as disciplinas exigidas para as especializações em Tradutor-Intérprete e Tradutor-Português-Inglês. Rio de Janeiro, 16 de fevereiro de 1978. " 
Logo no início do seu percurso à frente da nova habilitação, a profa. Candida passou a dispor de um aluno monitor, contratado pelo departamento para auxiliar nas aulas de interpretação simultânea em vista de sua experiência recente como intérprete da USAID, ligada ao Departamento de Estado, em Washington, onde fora treinado na prática por um dos intérpretes do presidente Nixon (Bekenn, depoimento pessoal). André Luiz Bekenn era então um jovem estudante de Engenharia Mecânica que cursava Alemão como disciplina eletiva de Letras, e sua aproximação com o departamento se deveu ao fato de ter sido eleito representante de turma dessa disciplina. Em pouco tempo, a profa. Candida passou a se dedicar exclusivamente à área da tradução, iniciando um percurso que seria muito bem-sucedido e foi registrado por Martins no artigo já citado (Martins, 2007). André Bekenn assumiu então a área de interpretação, passando em poucos anos de monitor a professor pleno e coordenador, e tornando-se uma figura central do curso nesse meio século de história.

Segundo informação do Catálogo Geral, em 1970 o Departamento de Letras já contava "com as instalações de um laboratório de Línguas de moderno equipamento eletrônico com 36 cabines individuais [...] que permite a aplicação dos métodos áudio-visuais mais avançados" (Catálogo Geral PUC-Rio, 1970, p. 63). Esse laboratório começou a ser usado nas aulas de simultânea e, com o tempo, se tornaria conhecido como o "Laboratório de Interpretação", sendo reformado em 2013 (abaixo, fotos do laboratório em 1977 e após a reforma de 2013. Nesta última, à direita, notar a cabine no fundo da sala). 

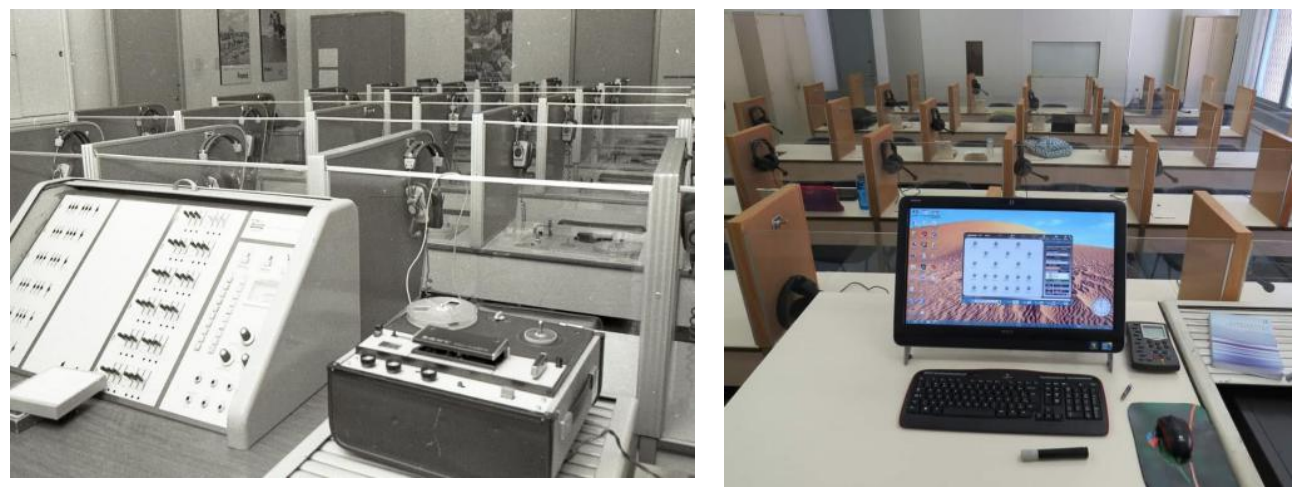

Para viabilizar a prática da interpretação simultânea pelos alunos em sala, a ocupação das "36 cabines individuais" era restrita à metade, em lugares alternados -- configuração essa que se mantém em parte até hoje, mesmo depois da instalação de uma cabine propriamente dita no fundo da sala.

Para a preparação do material didático para as aulas de interpretação, André Bekenn estabeleceu desde cedo uma parceria com a Embaixada dos Estados Unidos, de quem passou a receber periodicamente gravações sobre a história e a cultura americanas e sobre notícias científicas, imprimindo ao curso um enfoque na cultura geral e na área técnicocientífica. Esse foco, claramente reforçado por sua própria bagagem e pendor intelectual, coadunava-se perfeitamente, por um lado, com as demandas do mercado nacional naquele momento histórico e, por outro, com as necessidades de um corpo discente que tinha mais afinidade com as ciências humanas e que, portanto, se ressentia de uma maior familiarização com a área técnico-científica.

Quanto à elaboração inicial do currículo da nova habilitação, é preciso lembrar que havia poucas escolas no mundo que formavam intérpretes, e que a literatura sobre interpretação e sobre a formação desses profissionais era escassa e de difícil acesso considerando os meios de comunicação vigentes nos anos 1970 (para mais informações, ver Pagura, 2010). Candida Bordenave relata ter se inspirado no curso da Universidade 
de Georgetown, que ela frequentara e onde fora aluna do seu fundador, Léon Dostert, o intérprete "responsável pela implantação da interpretação simultânea em Nuremberg e na ONU" (Pagura, 2010, p. 74). Segundo relato pessoal, ela procurou trocar experiências com outros cursos universitários que estavam sendo criados no Brasil na mesma época, impulsionados pela mesma LDB, como a Faculdade Ibero-Americana em São Paulo, a PUCRS, em Porto Alegre, e a UFRGS, na mesma capital, embora reconheça que essa troca não foi sistemática.

André Bekenn, por sua vez, relata ter se baseado em sua própria experiência e bom-senso para nortear sua atuação docente e logo desenvolveu uma metodologia própria, que reconhecia acima de tudo a importância de fomentar nos estudantes, por um lado, autoconfiança e autodisciplina e, por outro, sua curiosidade intelectual. Seu estilo ao mesmo tempo afetivo e rigoroso incluía o uso de bordões claros e sucintos que ficaram gravados na memória dos seus alunos. Assim, por exemplo, procurava resumir em palavras facilmente assimiláveis o complexo processo da simultânea ao recomendar para "Pensar no que o orador está falando e falar o que você está pensando" (ver abaixo foto de anotações em caderno de ex-aluna). Essa frase capta com extrema lucidez e simplicidade a ideia central da Teoria Interpretativa da Tradução de Danika Seleskovitch, da ESIT (Escola de Intérpretes e Tradutores da Sorbonne, em Paris), que privilegia o sentido em detrimento da palavra e começou a ganhar força justamente nos anos 1970 (Pagura, 2010; Seleskovitch, 1999, p. $60)$. 


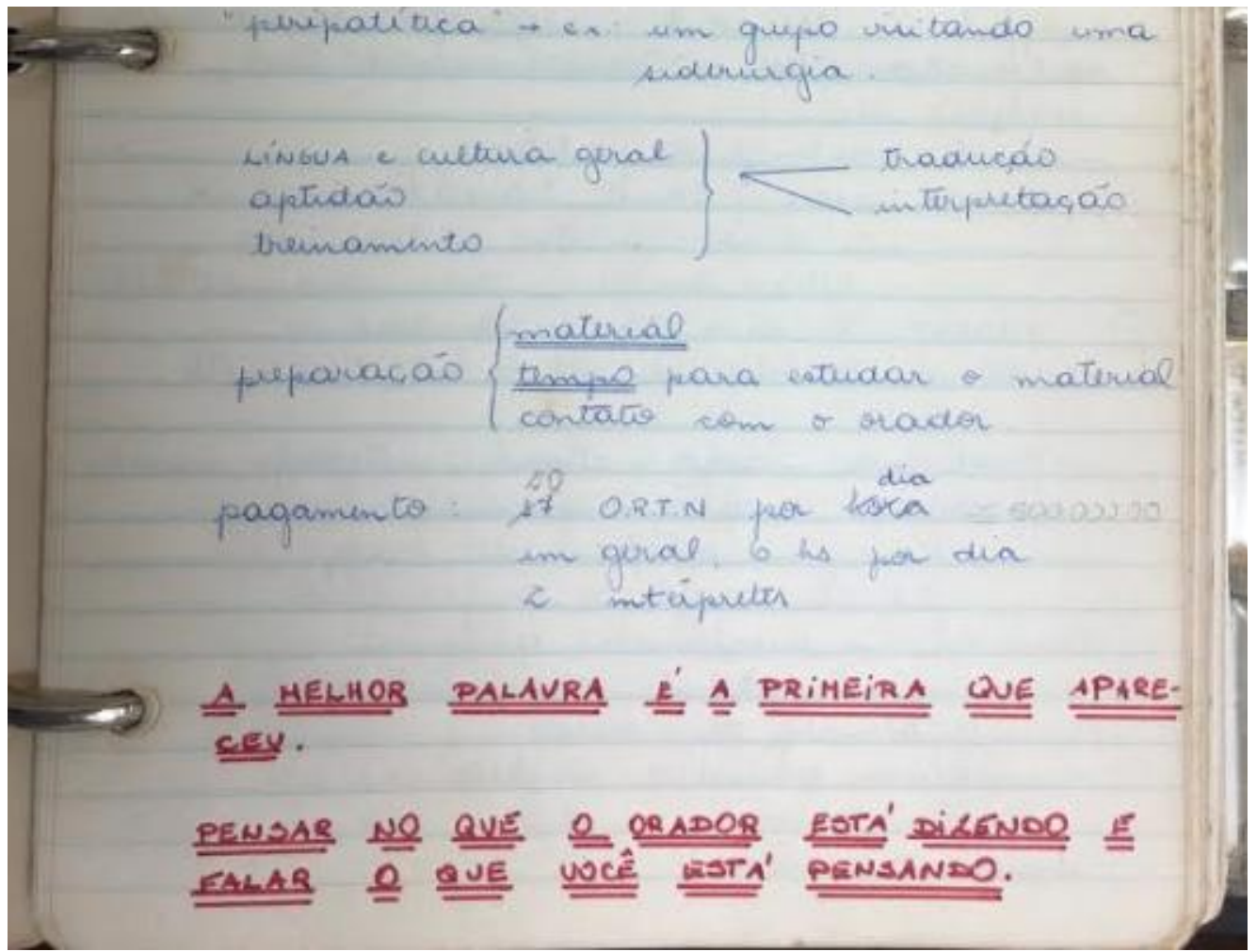

Ao mesmo tempo em que o curso se estabelecia e começava a formar novos profissionais, no decorrer dos anos 1970, o mercado de eventos ganhava impulso no país. Em 1971, deu-se a fundação da primeira associação de intérpretes brasileira, em São Paulo (hoje Associação Profissional de Intérpretes de Conferência, ou APIC). No Rio de Janeiro, o mercado era controlado desde os anos 1950 por um pequeno grupo de intérpretes liderado por Edith van de Beuque. Esse fato, relatado por Wyler (2003, p. 46) e, em mais detalhes, por Pagura (2010, p. 72), ganha especial relevância no contexto do surgimento e da consolidação do curso de intérpretes da PUC-Rio, pelos motivos tão bem expostos por Pagura (2010, p. 76), a quem passo a palavra: 


\begin{abstract}
Assim, ao recusar [...] Maria Candida Bordenave, do Rio, Edith van de Beuque, de certo modo, propiciou, ainda que indiretamente e, obviamente, sem nenhuma intenção, os dois principais elementos responsáveis pela quebra da hegemonia de seu grupo no Brasil: a criação da APIC em São Paulo, em 1971, e a implantação do programa de formação de intérpretes da PUC-Rio, coincidentemente no mesmo ano que produziria seus concorrentes mais diretos no Rio, como Sylvia Nobrega, entre muitos outros.
\end{abstract}

Sylvia Nobrega, segundo Wyler "a primeira intérprete a disputar o mercado do Rio com Edith van de Beuque" (Wyler, 2003, p. 47), foi aluna da terceira turma da habilitação e juntou-se a uma colega de turma, Regina Silveira, para fundar a Intergroup, uma empresa de eventos que passou a absorver os egressos do curso, estabelecendo desde logo uma ponte entre academia e mercado que só fez se fortalecer com o tempo e acabou se configurando como uma característica distintiva do curso. Foi também em parte graças a essa comunicação com o mercado que o curso foi sendo aprimorado, com a criação de novas disciplinas e o aumento da carga horária das disciplinas práticas, em alguns casos por sugestão dos exalunos que ingressavam no mercado e se ressentiam de certas lacunas em sua formação. É essa fase de crescimento e consolidação que exploraremos a seguir.

\title{
Expansão e consolidação: os anos de 1980 e 1990
}

Por mais de uma década, até 1985, o curso incluiu várias disciplinas de tradução escrita e somente duas disciplinas práticas específicas interpretação consecutiva e interpretação simultânea, a princípio somente do inglês para o português. A prática de interpretação de retour, do português para a língua estrangeira, somente foi sistematizada com a introdução da disciplina Versão Oral, na reforma de 1985, seguindo a tendência de atender a demanda do mercado discutida por Seleskovitch em artigo de 1999 (Seleskovitch, 1999, p. 62-63).

O corpo docente cresceu timidamente naqueles anos, já inaugurando um processo de retroalimentação que se tornaria uma tradição, ou seja, a prática de incorporar na equipe os próprios egressos do curso que demonstrem interesse na carreira acadêmica. Dois nomes 
merecem ser lembrados por sua contribuição nessa fase crucial de expansão e consolidação do currículo: Angela D'Aguiar, que se formara na segunda turma do novo bacharelado, e Silvia Becher, que viria a ser sua aluna alguns anos depois. Ambas já eram professoras de inglês do Departamento quando foram convidadas por André Bekenn, em momentos diferentes, para integrar sua equipe. Angela também foi aluna do curso de interpretação de Georgetown e, por um longo período, com seu estilo cativante, foi a única responsável pela disciplina de interpretação consecutiva, até seu desligamento em 1996, quando a sucedi. Já Silvia foi aluna de Angela e André no final dos anos de 1970 e entrou na equipe por sua competência e sua proficiência avançada em língua inglesa, para assumir a disciplina Versão Oral, que sofreria vários acréscimos de carga horária ao longo dos anos e permaneceu sob sua responsabilidade até seu falecimento precoce em 2014.

Em 1985 houve a primeira verdadeira reforma curricular desde a introdução das novas habilitações do bacharelado, que se caracterizou pelo aumento da carga horária das disciplinas específicas, por um lado, e pela introdução de quatro disciplinas instrumentais, visando a dar maior respaldo às disciplinas práticas, por outro.

A primeira delas foi Dicção e Impostação da Voz, ministrada por uma fonoaudióloga, com um conteúdo que conquistou lugar cativo nas sucessivas reformas curriculares devido à importância dos cuidados com a voz para o intérprete de conferências. A segunda disciplina, do Departamento de Psicologia, inicialmente se chamou Tópicos Especiais em Psicologia -- Atenção e Concentração: Teoria e Prática e posteriormente foi renomeada somente Atenção e Concentração. A disciplina Estruturas Orais do Português (posteriormente renomeada Português para Intérpretes) surgiu como a contrapartida oral da disciplina Português para Tradutor, que fazia parte do currículo do bacharelado em tradução e ainda era obrigatória também para a habilitação de intérprete. Era ministrada por professoras de português do Departamento de Letras, também ex-alunas do curso, e tinha por objetivo apresentar e discutir os diferentes registros e características da língua falada em situação de conferência. A quarta 
disciplina instrumental introduzida foi Discurso Oral para Intérpretes, disciplina ministrada em inglês por um professor americano de política internacional, que visava aprimorar a fluência e o vocabulário em inglês discorrendo sobre assuntos da atualidade.

Essas quatro disciplinas instrumentais sofreram várias alterações nas sucessivas reformas curriculares, que serão descritas a seguir, mas seu conteúdo nunca deixou de ser oferecido de alguma forma no curso da PUC-Rio, dada a convicção do corpo docente sobre sua importância para ajudar a desenvolver as habilidades técnicas do intérprete de conferências. Quanto às disciplinas específicas, além do aumento da carga horária de interpretação simultânea e consecutiva, foi introduzida a disciplina Versão Oral, como mencionado anteriormente.

Essa configuração da grade curricular como um todo se manteve com poucas alterações até a próxima grande reforma curricular, em 2015.

Em 1988, diante da baixa procura da habilitação pelos alunos de Letras -seja por genuína falta de interesse na área, seja por não atingirem o nível mínimo de inglês exigido - foi criada a Coordenação de Cursos de Extensão em Letras (Martins, 2007, p. 181), que possibilitou oferecer para candidatos externos as vagas ociosas do curso. Os alunos de extensão seguiam a mesma periodização dos alunos de Letras, cursando somente as disciplinas específicas e, como tal, não faziam jus ao diploma de graduação, naturalmente, mas recebiam um certificado emitido pela Coordenação Central de Extensão (CCE). Nesse certificado constava o período letivo, a média final e a carga horária total do "Curso de Extensão 'Formação de intérpretes de conferência inglês-português', ministrado pelo Departamento de Letras e administrado pela CCE".

Enquanto os alunos de Letras, em número cada vez menor, ingressavam pela via do Vestibular, os alunos da extensão eram selecionados diretamente pelo prof. André mediante entrevista e análise do currículo, em que eram valorizadas especialmente, além do domínio do inglês, a bagagem cultural e a vivência no exterior. Embora não houvesse a exigência de uma segunda língua estrangeira, o domínio de outro idioma também contava favoravelmente na seleção, face às características do 
mercado, e os alunos com esse perfil sempre foram incentivados a praticar também o terceiro idioma (que às vezes era, na verdade, sua língua materna ou sua língua estrangeira mais forte). Dessa forma, entre os exalunos do curso há um número considerável de intérpretes que, embora oficialmente formados no par inglês/português, trabalham também, ou principalmente, com espanhol, francês, italiano, alemão e até russo.

O curso de extensão tinha duração de 2 anos (4 módulos oferecidos em 4 semestres consecutivos), e a carga horária total foi aumentando paulatinamente entre os anos de 1988 e 2003, passando de 720 para 840 horas, com poucas alterações das disciplinas introduzidas na reforma de 1985.

Em 2003, com vigência a partir de 2004, a coordenação do curso decidiu, junto com a direção do Departamento de Letras, transformar o curso de interpretação, que já praticamente não tinha alunos da Graduação, em Curso Sequencial (oficialmente denominado Curso Superior de Complementação de Estudos em Interpretação de Conferências), uma nova modalidade de curso superior homologada pelo MEC em 1998. Embora esse novo formato (assim como o formato de curso de extensão) facultasse o ingresso de alunos portadores de diploma de nível médio, na prática os alunos selecionados sempre tiveram, em sua grande maioria, graduação já concluída ou em andamento, geralmente na área das ciências humanas e sociais, mas também, em alguns casos, na área técnico-científica.

Nessa configuração, que perdurou somente até 2007, a carga horária foi acrescida de mais 30 horas em Versão Oral, chegando a 870 horas no total, assim distribuídas: 8 disciplinas específicas, perfazendo 630 horas (Simultânea I e II, Consecutiva I e II, Versão Oral I e II e Estágio Supervisionado I e II), e as 4 disciplinas instrumentais descritas anteriormente, com 240 horas. Uma delas, a disciplina Discurso Oral para Intérpretes, teve seu nome alterado para Atualidades Internacionais, visando a "melhor refletir seu conteúdo programático" (fonte: Projeto de Alteração do Curso Superior de Complementação de Estudos em Interpretação de Conferências, Departamento de Letras, PUC-Rio). 


\title{
Maturidade: os anos 2000
}

$\mathrm{Na}$ virada do milênio, o mercado de interpretação continuava em franca expansão, mas a interpretação como objeto de estudo ainda era relativamente nova. Como informa Pagura (2010, p. 11):

\begin{abstract}
Ainda que as pesquisas da área apareçam ocasionalmente em periódicos relacionados aos Estudos da Tradução, o primeiro (e, praticamente, único) periódico específico, com alcance internacional, da área de Estudos da Interpretação (Interpreting: International Journal of Research and Practice in Interpreting) foi lançado em 1996.
\end{abstract}

O curso da PUC-Rio há muito já era referência em formação de intérpretes, e a competência e o profissionalismo dos seus egressos eram amplamente reconhecidos no mercado, a tal ponto que "uma lista de exalunos da instituição seria quase equivalente a uma lista dos intérpretes profissionais em atuação no Rio de Janeiro" (Pagura, 2010, p. 165). Já não predominava no meio profissional a visão de que "um intérprete já nasce intérprete" (Pagura, 2010, p. 15) ${ }^{4}$, dispensando, portanto, uma formação acadêmica específica.

Academicamente a área também amadurecera, adotando definitivamente a expressão "formação de intérpretes" em detrimento de "treinamento de intérpretes", como se dizia nos primórdios da atividade e como ficou registrado não só nos Catálogos de Curso dos primeiros anos, mas até mesmo na primeira Dissertação de Mestrado do Brasil que se debruçou sobre a interpretação de conferência. Defendida em 1982 no Departamento de Letras da PUC-Rio por Clarisse Sieckenius de Souza, ela mesma intérprete profissional e ex-aluna do curso, foi intitulada "Fundamentos teóricos iniciais para o ensino da língua-meta em programa de treinamento de intérpretes simultâneos" (grifo meu). Esse estudo pioneiro, por sinal, serviria de base para a referida disciplina Estruturas Orais do Português (posteriormente Português para Intérpretes), que seria introduzida em 1985.

\footnotetext{
${ }^{4}$ Em referência a uma declaração de Jean Herbert reconhecendo o papel das escolas na formação de intérpretes. Citação retomada em Araujo, 2017, p. 9.
} 
É um fato, porém, a defasagem com que a área da interpretação conquistou espaço nos eventos acadêmicos em relação à área da tradução no Brasil. No $1^{\text {o }}$ Encontro Nacional de Tradutores, por exemplo, um evento inaugural organizado pela profa. Candida Bordenave na PUC-Rio em 1975 (quando as duas habilitações ainda eram acopladas), a área da interpretação não foi minimamente contemplada, como também não o foi no $2^{\mathrm{o}}$ Encontro Nacional de Tradutores, realizado em 1985, também na PUC. ${ }^{5}$

A participação dos intérpretes nos eventos acadêmicos foi crescendo gradualmente desde então, mas foi somente em meados dos anos 2000, depois que a Abrates, antiga Associação Brasileira de Tradutores, mudou seu nome para Associação Brasileira de Tradutores e Intérpretes, que os intérpretes passaram a ter uma presença mais expressiva nos eventos. ${ }^{6} \mathrm{Em}$ 2013 foi realizado na USP, em São Paulo, o $1^{\mathrm{o}}$ Simpósio Brasileiro de Interpretação, SIMBI. Em 2015, o então já tradicional congresso internacional anual da Abrates inaugurou uma sala inteiramente dedicada à interpretação, que tem se mantido todos os anos, além de oferecer cabines de interpretação simultânea para os intérpretes novatos que desejarem praticar e receber feedback de seus pares mais experientes - ambos os grupos, por sinal, constantemente frequentados por intérpretes formados na PUC-Rio.

Foi nesse contexto de expansão da área de Estudos da Interpretação que uma nova reforma, em 2008, viria promover o curso a pós-graduação lato sensu, visto que ele já atendia à maioria dos requisitos para tal, como carga horária mínima (360 horas), titulação dos professores e vinculação a instituição de ensino superior credenciada. A mudança de status inaugurou uma fase de amadurecimento acadêmico que culminou com sua inclusão, em 2012, no Interpreting Schools and Programmes Directory da Associação Internacional de Intérpretes de Conferência (AIIC), um cadastro online de escolas que seguem as melhores práticas em programas de formação de

\footnotetext{
${ }^{5}$ Para informações detalhadas sobre o programa, ver Martins, 2007 e Bonaparte, 2008.

${ }^{6}$ Para mais informações sobre eventos de tradução e interpretação no Brasil, ver Vianna, 2017; Frota, 2006 e Bonaparte, 2008.
} 
intérpretes. ${ }^{7}$ Atualmente, com o fechamento do curso da PUC-SP, também incluído no cadastro, o curso da PUC-Rio é o único programa da América do Sul em funcionamento listado no site. ${ }^{8}$

Explica Branca Vianna (2017, p. 6), que passou a integrar o corpo docente em 2005 e alguns anos depois tornou-se a representante brasileira no AIIC Training and Professional Development, órgão da Associação Internacional responsável pelas informações publicadas:

\begin{abstract}
Os cursos interessados em participar do cadastro respondem a quase quarenta perguntas sobre currículo, corpo docente, uso de tecnologia, combinações linguísticas, exames de aptidão e finais, número de diplomas conferidos versus número de candidatos aceitos e muitas outras. O questionário é bastante detalhado, oferecendo aos potenciais alunos uma fonte de informação riquíssima, ao escolher onde estudar.
\end{abstract}

A pós-graduação lato sensu, também chamada de especialização, preservou a vocação profissionalizante do curso, focada na formação de profissionais prontos para atuar no mercado, mas também representou uma significativa contribuição para a área de Estudos da Interpretação no Brasil, ao incorporar a exigência do MEC de elaboração de um trabalho de conclusão de curso (TCC), no formato de monografia. O TCC pode ser uma análise de desempenho ou uma pesquisa bibliográfica. No primeiro caso, o aluno deve efetuar uma autoavaliação do próprio desempenho durante uma interpretação em situação de estágio ou conferência simulada, desenvolvendo uma reflexão teoricamente fundamentada sobre todo o processo, desde a preparação até a interpretação propriamente dita. A outra possibilidade é escolher um tema relevante na área, que será então pesquisado e elaborado, às vezes mediante entrevistas ou questionários, com a orientação de um professor. Alguns dos temas de monografias de alunos que reverteram em artigos publicados ou apresentações em congressos são, por exemplo: a preparação do intérprete, a voz como instrumento profissional, a interpretação de tribunal, a interpretação nas

\footnotetext{
${ }^{7}$ Para uma discussão dos critérios de inclusão, ver Araujo, 2017.

8 Ver no endereço https://aiic.net/directories/schools/255/pontificia-universidade-catolica-do-rio-dejaneiro-puc-rio/especializacao-em-interpretacao-de-conferencias
} 
redes sociais, a interpretação como processo criativo, a interpretação comercial e comunitária no Brasil etc.

Essa reforma incluiu novo aumento da carga horária de Versão Oral, elevando a carga total de 870 para 930 horas, o nível mais alto em toda a história do curso. A duração do programa foi mantida em 4 semestres letivos. Outra alteração foi a substituição da disciplina Atualidades Internacionais (que era de 60 horas) por Pesquisa Temática e Princípios Teórico-pragmáticos (de 30 horas cada), nomes que espelhavam mais fielmente o conteúdo que já vinha sendo oferecido pela disciplina anterior. No caso da primeira, Pesquisa Temática, o objetivo ainda era familiarizar o aluno com os temas da atualidade, porém com foco mais explícito em levantamento de terminologia e elaboração de glossários. A segunda disciplina, que seria mais apropriadamente denominada Estudos da Interpretação na reforma seguinte, visava a congregar as leituras e reflexões de cunho teórico, sempre aliadas aos aspectos práticos e princípios éticos da profissão e do mercado, que antes eram dispersas ao longo do curso. As disciplinas Estágio Supervisionado I e II também tiveram o título alterado, respectivamente para Interpretação Simultânea III e Prática Avançada de Interpretação, visto que os estágios propriamente ditos acontecem fora da grade curricular.

Nesse ponto, vale um comentário mais detalhado sobre a prática de estágios no âmbito do curso. Graças à posição privilegiada do programa dentro de uma universidade que se pauta pelo "intercâmbio entre culturas e saberes" ${ }^{\prime \prime}$, desde as primeiras turmas, já no começo dos anos 1970, os alunos sempre tiveram oportunidade de fazer estágios de interpretação (tanto na modalidade simultânea quanto na consecutiva) em conferências realizadas na PUC. Os estágios, sempre não remunerados, são organizados com toda a transparência entre as partes envolvidas, respeitando as condições de trabalho preconizadas pelo mercado profissional de interpretação de conferências. Sob a coordenação de um professor, que faz as vezes de intérprete-coordenador, o aluno tem a chance de colocar em prática, em situações reais, as habilidades desenvolvidas em aula,

\footnotetext{
9 “Missão e marco referencial”, http://www.puc-rio.br/sobrepuc/historia/. Acesso em 08/05/18.
} 
expandindo o aprendizado para além da expertise técnica e incluindo aspectos relacionados ao profissionalismo em sentido mais amplo, como o relacionamento com o cliente, o orador, o público e o colega, e todas as questões éticas e sociais derivadas dessas diferentes interações.

Como seria de se esperar, o curso de pós-graduação, que exige para o ingresso uma graduação completa, passou a atrair alunos mais maduros e já inseridos, em sua maioria, no mercado de trabalho. Se, por um lado, essa maturidade e experiência profissional são positivas para a formação do intérprete, por outro, acarretam uma situação de menor disponibilidade de tempo, o que acabou se refletindo em problemas de assiduidade e participação nas aulas por parte de alguns alunos. Ao mesmo tempo, dada a elevada carga horária total, o curso representava um significativo investimento financeiro, o que, aliado à inegável crise econômica, levou a uma queda gradual da procura.

Esse fato ensejou uma profunda reflexão por parte do corpo docente, levando a uma reformulação que reduziu significativamente a carga horária e, portanto, a duração do curso, de modo a torná-lo mais acessível na nova conjuntura.

Chegou-se à conclusão de que as novas metodologias de ensinoaprendizagem, que já vinham sendo adotadas pelos professores, aliadas às modernas tecnologias e recursos online amplamente disponíveis, não mais justificavam a prática extensiva em sala de aula. A nova metodologia implementada visava ao desenvolvimento da expertise em interpretação através de exercícios que trabalham as diversas habilidades isoladamente (Gillies, 2013) e da gestão da capacidade de processamento cognitivo (Gile, 1992). Tornaram-se centrais, nesse momento, os conceitos de aprendizagem autônoma (Horvárth, 2005, apud Gondar, 2017) e de prática deliberada, uma atividade altamente estruturada, com objetivos específicos, e que o aluno deve prosseguir em casa, por conta própria, a partir das observações do professor (Bao, 2015).

Nesse novo modelo, foi proposto um currículo de 400 horas em dois semestre letivos (mais um semestre para a elaboração da monografia), com recomendação de mais 80 horas não presenciais de estudo individual ou entre pares. 
Dessa forma, na nova grade curricular, que vigorou apenas para a turma de 2016, as disciplinas práticas foram assim distribuídas: Interpretação Consecutiva I (60h) e Consecutiva II (30h); Interpretação Simultânea para Língua Materna I (60h) e II (30h); Interpretação Simultânea para Língua Estrangeira (60h) e Prática de Cabine I e II (20h cada) -- estas duas últimas inteiramente dedicadas a conferências simuladas, com palestrantes convidados, em consonância com o aprendizado situado proposto por Kiraly (Kiraly, 2000, apud Araújo, 2017), que visa a exercitar uma atitude profissional, indo além dos aspectos meramente linguísticos. Como explica Araujo (2017, p. 29) em sua dissertação de Mestrado sobre os cursos de formação de intérpretes no Brasil:

\begin{abstract}
Um modelo socioconstrutivista para a sala de aula de interpretação, tomando por base o apresentado por Kiraly, poderá se materializar da seguinte maneira: para que os aprendizes sempre estejam envolvidos em situações profissionais, desde o início da formação serão realizadas conferências simuladas pelo menos uma vez por mês com a participação de todos - primeiramente em consecutiva e depois em simultânea. Essas conferências podem ser eventos criados pelos próprios alunos, que estarão todos envolvidos no projeto.
\end{abstract}

Além dessas, foi introduzida mais uma disciplina prática, que recebeu o nome de Outras Modalidades de Interpretação (30h). O conteúdo programático visa a atender peculiaridades do mercado, onde são cada vez mais comuns as situações de interpretação fora da cabine, vale dizer, acompanhamento com e sem equipamento portátil ${ }^{10}$, interpretação sussurrada alternando com consecutiva intermitente (para autoridades ou pequenas reuniões, por exemplo) e interpretação remota, através de videoconferência ou em plataforma digital específica.

As disciplinas instrumentais, que passaram a incluir também algumas horas de prática integrada ao tema em questão, foram divididas da seguinte maneira: Habilidades Instrumentais (30h) reúne na mesma rubrica preparação vocal, gerenciamento do estresse e exercícios de

\footnotetext{
10 Equipamento de interpretação simultânea compacto, que consiste apenas em um transmissor, microfone e receptores com fones de ouvido, dispensando cabine e cabos.
} 
concentração e memória. Aperfeiçoamento Linguístico (30h) visa a desenvolver o registro e a terminologia próprios de conferências nas línguas de trabalho, bem como a capacidade de pesquisa e elaboração de glossários. Finalmente, Estudos da Interpretação (30h) contempla desde os marcos históricos da interpretação até a sistematização dos fundamentos teóricos desse campo de estudos, incluindo metodologia de pesquisa com vistas à elaboração do projeto de monografia.

A seleção dos candidatos passou a ser feita com uma banca de quatro professores e a incluir um teste de aptidão nas duas línguas.

Esse momento de profunda reflexão e mudança foi a última grande contribuição do prof. André Bekenn na qualidade de coordenador, pois logo em seguida, em julho de 2016, surpreendeu a todos com a decisão de se aposentar, após 45 anos de docência integralmente dedicada ao Curso de Formação de Intérpretes da PUC-Rio. A coordenação ficou a meu cargo, pois eu já vinha trabalhando ao seu lado havia vários anos, e naquele mesmo ano decidi, junto com todo o corpo docente, promover nova adequação curricular -- como pretendemos continuar fazendo regularmente para acompanhar as demandas do mercado de trabalho e as novas propostas pedagógicas e abordagens teóricas que venham a surgir na área de Estudos da Interpretação.

Assim, procedemos a um redimensionamento da carga horária, que subiu para 510 horas, com a inclusão, entre outras, das disciplinas práticas Tópicos em Engenharia do Petróleo e Tópicos em Relações Internacionais (10 horas cada). Essas disciplinas pretendem oferecer um panorama de duas áreas do conhecimento especialmente relevantes no mercado de interpretação, aliado à oportunidade de prática de interpretação em conferências proferidas pelo respectivo professor especialista e palestrantes convidados.

Foram introduzidas ainda 30 horas divididas em Estudo Dirigido I e II, em semestres sucessivos, para atividades teórico-práticas supervisionadas e feedback individual. 
Os professores, quase todos membros das duas principais associações de intérpretes (AIIC e APIC), mantêm uma colaboração estreita com as associações e frequentemente convidam outros membros para discutir com seus alunos assuntos relevantes para a formação e o mercado, além de abrirem as portas da instituição para eventos de interesse da classe. Vale ressaltar também que todos os membros do corpo docente investem constantemente em educação continuada, principalmente através dos cursos de tipo Training of Trainers promovidos pela AIIC.

O programa inaugurou desde cedo a prática de oferecer cursos e palestras fora da grade curricular, que já se tornaram tradição. O primeiro de que se tem notícia aparece no Anuário PUC-Rio de 1977 entre os cursos de Extensão oferecidos pelo Departamento de Letras, e chamou-se "Treinamento para Intérpretes de Inglês". Nas décadas seguintes continuaram sendo oferecidos cursos semestrais extracurriculares, como aulas de reciclagem inglês-português e prática de interpretação de francês e de espanhol, de acordo com a demanda.

Em 2016 o curso organizou o “I Forum PUC-Rio de Interpretação de Conferência: da sala de aula ao mercado", que incluiu palestras de exalunos sobre os temas desenvolvidos nas suas monografias e uma mesaredonda sobre mercado de trabalho com a participação de intérpretes profissionais. $\mathrm{O}$ evento bilíngue, cujo modelo foi repetido no ano seguinte, com outros temas e convidados, foi aberto para estudantes, professores e profissionais, e contou com tradução simultânea pelos alunos formandos, que tiveram assim a oportunidade de mostrar seu desempenho aos colegas presentes.

Em 2017, três professores do curso foram convidados para organizar um número temático sobre interpretação do periódico Tradução em Revista, vinculado à linha "Linguagem, Sentido e Tradução" do Programa de PósGraduação em Estudos da Linguagem do Departamento de Letras da PUCRio. $\mathrm{O}$ interesse despertado foi tão grande que resultou em dois números temáticos sucessivos.

Como vimos através do caso da PUC-Rio, o novo campo disciplinar dos Estudos da Interpretação, cada vez mais desvinculado dos Estudos da 
Tradução, tem tido uma trajetória de expansão e amadurecimento, evidenciada pela consolidação dos cursos e pelo número de eventos e sessões temáticas em congressos e publicações. O "paradigma de formação" descrito por Mackintosh (1999), em artigo sobre a formação de intérpretes, está claramente estabelecido. Apesar de ainda haver muitos aspectos carentes de pesquisa, a área de formação é hoje mais estruturada e teoricamente fundamentada, como espero ter demonstrado neste artigo, ao descrever a evolução do curso de Formação de Intérpretes da PUC-Rio. No entanto, o mercado de interpretação e os cursos de intérpretes no Brasil, e em especial no Estado do Rio de Janeiro, ainda estão sentindo os efeitos da crise econômica, com a diminuição do número de eventos, no primeiro caso, e do número de candidatos, no segundo. Esperamos que ventos melhores soprem nos próximos anos para que a área como um todo possa continuar seu percurso de crescimento.

\section{Referências}

ANUÁRIO PUC-Rio, anos 1972, 1977.

ARAUJO, Denise de Vasconcelos. Os cursos de formação de intérpretes no Brasil e as melhores práticas da Associação Internacional de Intérpretes de Conferência: um caminho para a profissionalização. 2017. 95p. Dissertação (Mestrado) - Programa de Pós-graduação em Estudos da Linguagem, Departamento de Letras, PUC-Rio.

BAO, Chuanyun. Pedagogy. In: Mikkelson, H. and Jourdenais, R. The Routledge Handbook of Interpreting. London and New York: Routledge, 2015, p. 400-416.

BONAPARTE, Elizabeth Cunha. I Encontro Nacional de Tradutores: a (re)construção da imagem da profissão do tradutor no Brasil. Tradução em Revista no. 5, 2008. Disponível em: <https://www.maxwell.vrac.pucrio.br/12707/12707.PDFXXvmi=>. Acesso em 4 de abril de 2018.

CATÁLOGO GERAL da PUC-Rio, anos de 1970, 1974, 1978, 1982, 1984, 1985.

CATÁLOGO DA GRADUAÇÃO PUC-Rio, 1999-2000. 
FROTA, Maria Paula. O GT de Tradução da ANPOLL: história e perspectivas, 2006. Disponível em:

$<$ http://letra.letras.ufmg.br/gttrad/anpoll.html $>$. Acesso em 2 de abril de 2018.

GILE, Daniel. Basic concepts and models for interpreter and translator training. Revised Edition. Amsterdam/Philadelphia: John Benjamins, 2009.

GILLIES, Andrew. Conference Interpreting: a student's practice book. London and New York: Routledge, 2013.

MACKINTOSH, Jennifer. Interpreters are made not born. Interpreting, Amsterdam/Philadelphia, Volume 4, Issue 1, 1999, p.67-80.

MARTINS, Marcia Amaral Peixoto. A institucionalização da tradução no Brasil: o caso da Puc-Rio. Cadernos de Tradução, Florianópolis, v. 1, n. 19, set. 2007, p. 171-192. Disponível em:

$<$ https://periodicos.ufsc.br/index.php/traducao/article/view/6997>. Acesso em: 30 de março de 2018.

PAGURA, Reynaldo José. A Interpretação de Conferências no Brasil: história de sua prática profissional e a formação de intérpretes brasileiros. 2010. 231p. Tese (Doutorado) - Faculdade de Filosofia, Letras e Ciências Humanas, Universidade de São Paulo, São Paulo.

PÖCHHACKER, Franz. Introducing Interpreting Studies. London and New York: Routledge, 2004.

SAWYER, David B. Fundamental aspects of interpreter education: curriculum and assessment. Amsterdam: John Benjamins, 2004.

SELESKOVITCH, Danica. The Teaching of Conference Interpretation in the Course of the Last 50 Years. Interpreting, Amsterdam/Philadelphia, Volume 4, Issue 1, 1999, p.55-66.

VIANNA, Branca. A atuação do Comitê de Formação e Atualização Profissional da AIIC no novo panorama de ensino e pesquisa no Brasil. Publicações i2B. Tópicos e contextos em interpretação, vol. 2, 2017. Disponível em $<$ http://www.interpret2b.com/publicacoes $>$. Acesso em 28 de março de 2018.

WYLER, Lia. Línguas, poetas e bacharéis: uma crônica da tradução no Brasil. Rio de Janeiro: Rocco, 2003. 


\title{
Resumo
}

O curso de Formação de intérpretes da PUC-Rio, que é hoje uma pósgraduação lato sensu com duração de um ano, foi inaugurado em 1968, com a criação da habilitação em revisor-tradutor-intérprete no Bacharelado em Letras. Este artigo visa a contribuir para a história e a pesquisa em interpretação ao descrever todas as reformas curriculares implementadas ao longo desses 50 anos, sempre correlacionadas com o momento histórico, a evolução da área de Estudos da Interpretação e as demandas do mercado de interpretação de conferências no Brasil.

Palavras-chave: História da interpretação no Brasil; formação de intérpretes; currículo; Estudos da Interpretação.

\begin{abstract}
The conference interpreter training course at PUC-Rio is today a graduate certificate program which started in 1968 as a major of the Department of Letters combining copy-editing, translating and interpreting. This paper wishes to contribute to the history and research on interpreting by describing all the curriculum changes implemented in the past 50 years. The historical moment, the evolution of the area of Interpreting Studies and the demands of the Brazilian conference interpreting market are also highlighted in view of these changes.

Keywords: History of conference interpreting in Brazil; interpreter training; curriculum; Interpreting Studies.
\end{abstract}

